ص ص21-9]

$$
\begin{aligned}
& \text { محدداث تدفقاث رأس المال الخاص } \\
& \text { في عدد من دول شرق أسيا }
\end{aligned}
$$

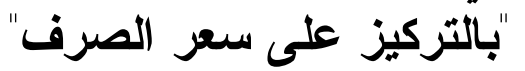

$$
\begin{aligned}
& \text { الدكتور سعدون حسين فرحان } \\
& \text { مدرس-قسم الاقتصاد } \\
& \text { كلية الادارة والاقتصاد-جامعة الموصل }
\end{aligned}
$$

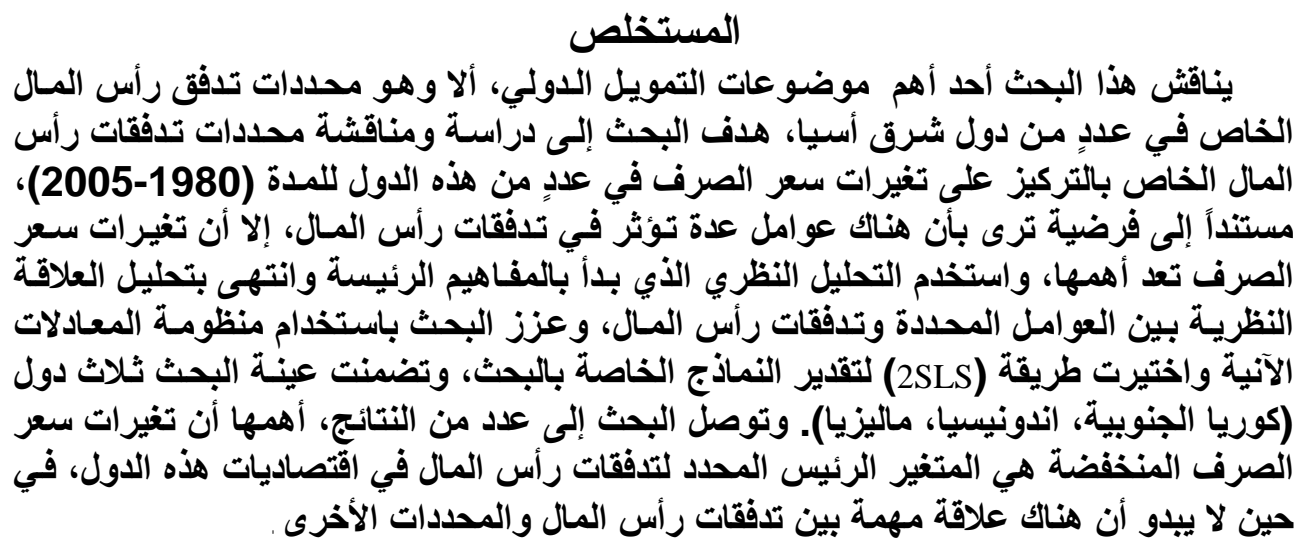

\title{
Determinants of Private Capital Flows in a Number of East Asian Countries with Special Reference to Exchange Rate
}

\author{
Sadoon Husieen Farhan (PhD) \\ Department of Business Administration \\ University of Mosul \\ Saadoonhuseen@yahoo.com
}

\begin{abstract}
This research discusses one of the most important subjects of international finance, the determinants of private capital flows in a number of East Asian Countries. The research aimed at studying and discussing the determinants of the Private Capital's Flows through focusing on the variations of Exchange Rate in several East Asian Countries for the period (1980 - 2005). It is hypothesized that there are many factors affecting the capital flows, and
\end{abstract}


the changes of Exchanges Rate are the most important among them. The research used the theoretical analysis started by the main concepts and ended with the analysis of the theoretical relationship between the determinant factors of the capital flows. The research is enhanced by using a set of instantaneous equations, (2SLS) method is selected to estimate the models of the research. The sample of this research involved three countries (South Korea, Indonesia and Malaysia). The research concluded some results; the most important is that the low variation in Exchanges rate is the main variable which determines the capital flows in the economies of these countries, while it is not seem that there is a significant relationship between Capital's Flow and the other determinants.

المقدمة

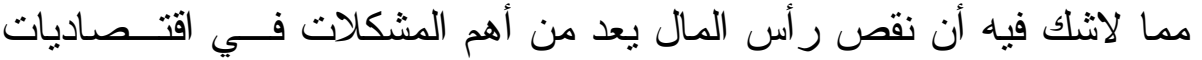

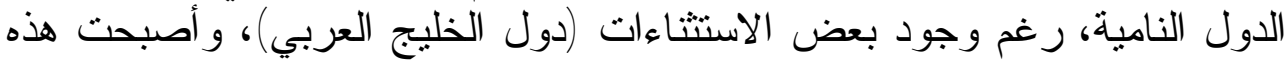

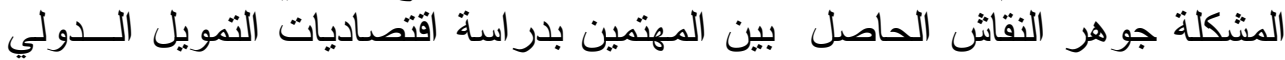
سو اء كانو ا باحثين أم هيئات ومنظمات دولية (صندوق النقا و البنك الدوليين)، وقدات

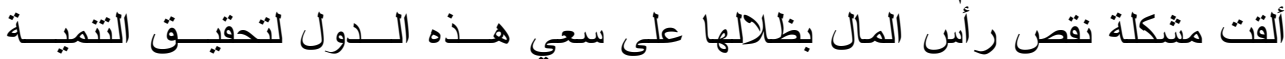

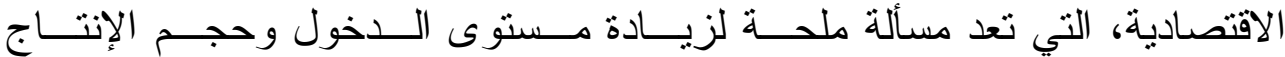

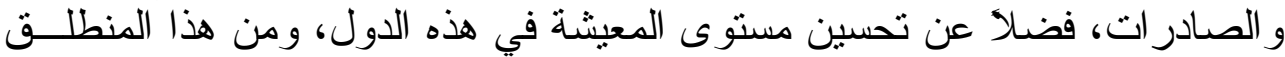

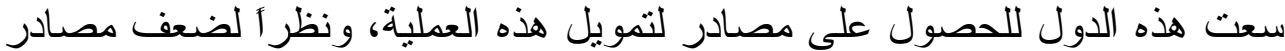

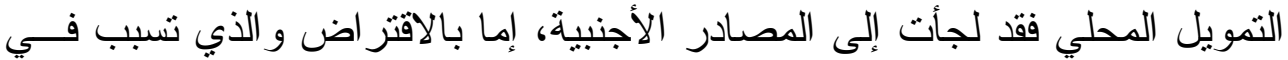

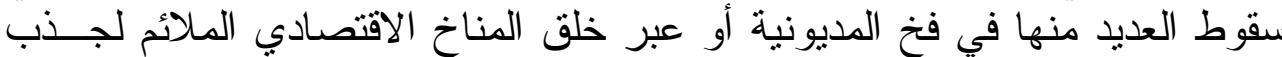

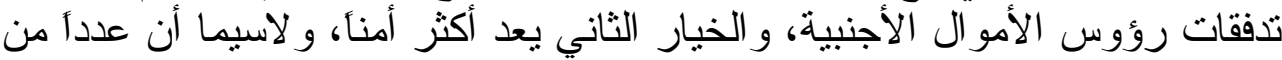

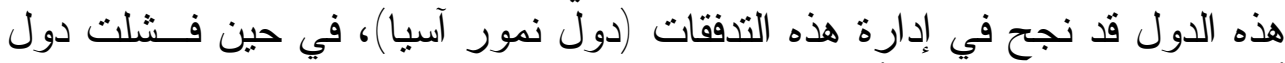

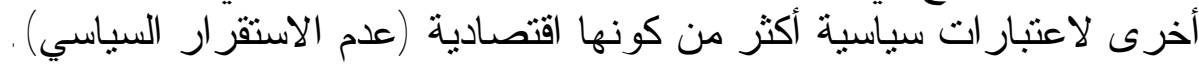

تعد در اسة محددات تدفقات رأس المال الخاص (بالتحديد ســعر الــصرف) أهمية البحث

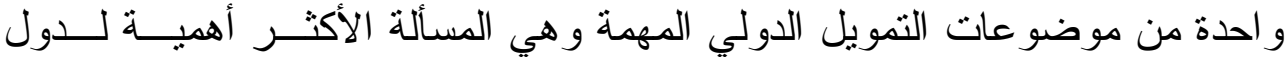

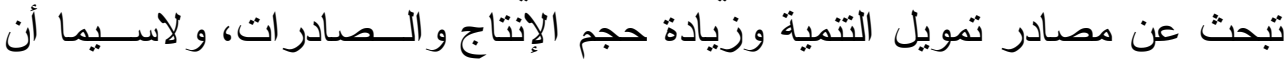

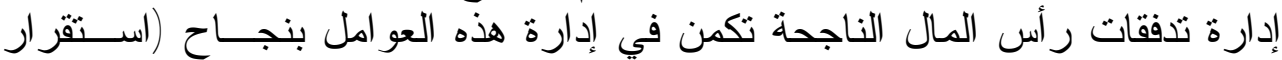

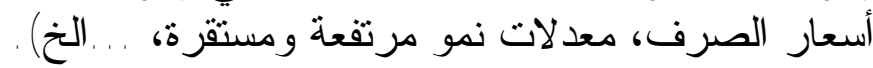

تتلخص مشكلة البحث في أن السير بعملية التتمية في العديد من الدول النامية

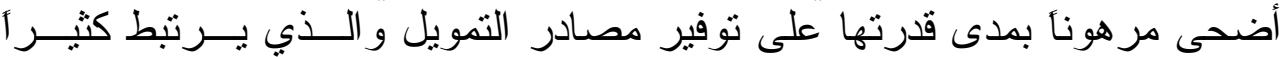

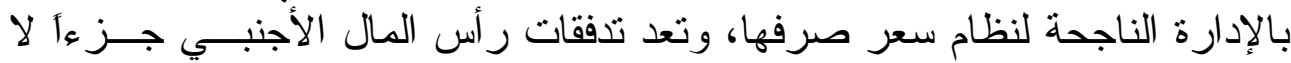
يتجز أ من هذه المصادر ، شرط أن تهدف إلى الاستثمار وليس إلى المضارئارية. 
يهدف البحث إلى دراسة وتحليل العوامل المؤثزة في تــدفقات رأس المــال

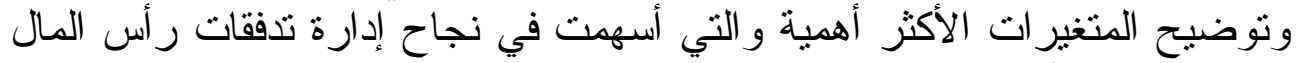
في دول شرق آسيا استتادأ إلى التحليل النظري و التجريبي.

فرضية البحث

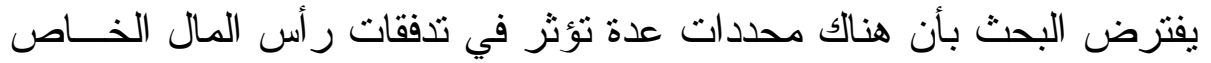
في دول شرق أسيا، إلا أن سعر الصرف يعد أهم هذه المحددات في هذه الدول.

ربط البحث بين جانبين، الأول: الإطار النظري الذي ابتدأ بالمفاهيم الأساسية

\section{منهج البحث}

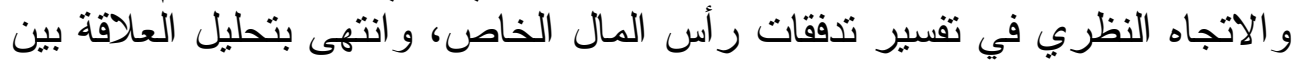

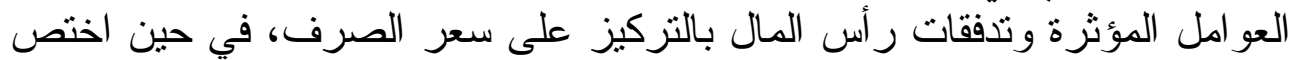

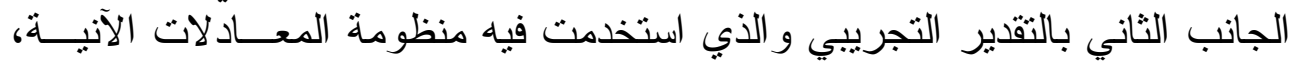

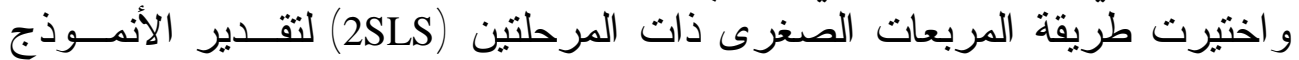

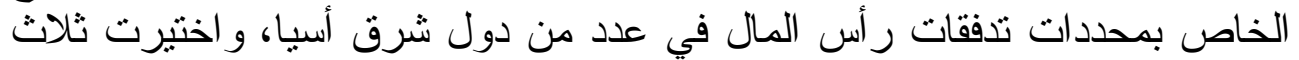

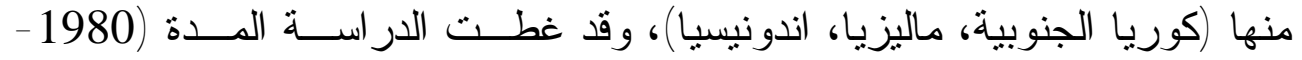
. (2005

الأسس النظريسـة لار اســـة تدفقات رأس المــال الخاص في دول شرق آسيا أولاً - مفهوم تدفقات رأس المال

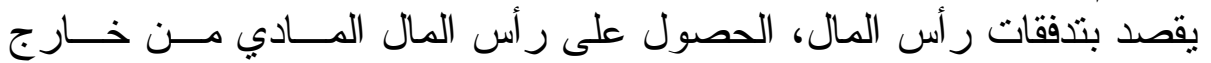

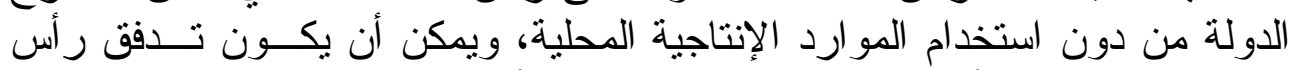

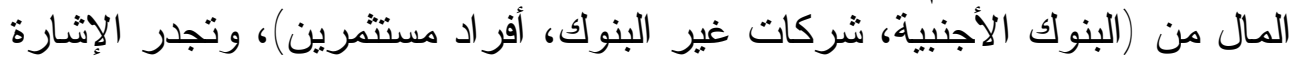

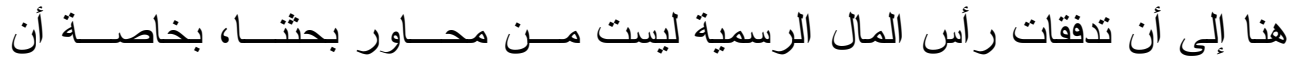

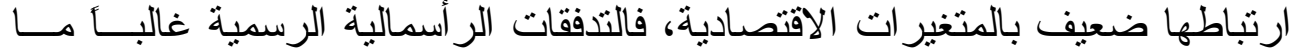

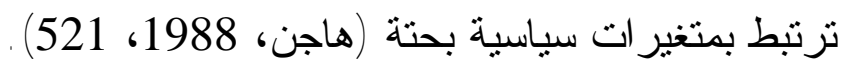
ثنانياً - أشكال تدفقات رأس المال الخاص تتخذ تدفقات رأس المال الخاص ثلاثة أثنكال رئيسة وهي بالثنكل الآتي:

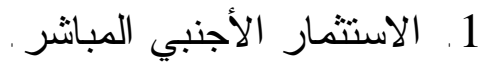

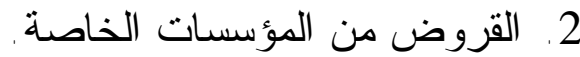
3. تدفقات رأس المال لأغر اض المضات الفاربة (تدفقات المدى القريب).

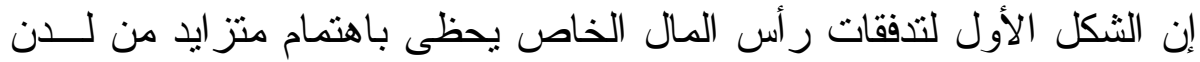

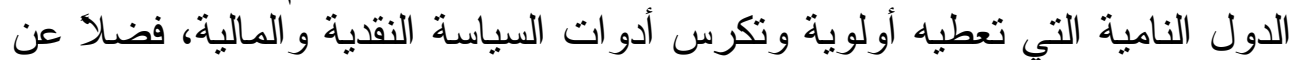

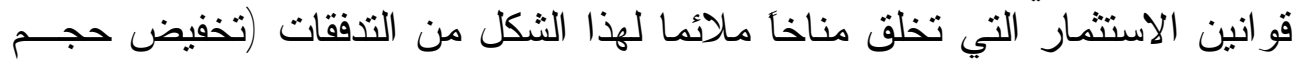




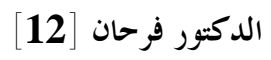

الضر ائب، رفع بعض الرسوم التي تعيق تدفق الاستثمار الأجنبي... و غير ها مـنـ

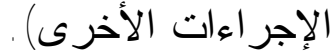

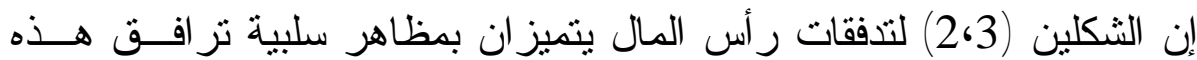

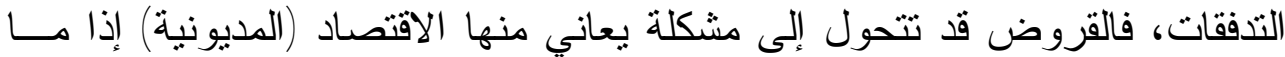

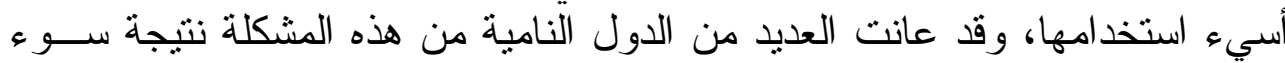

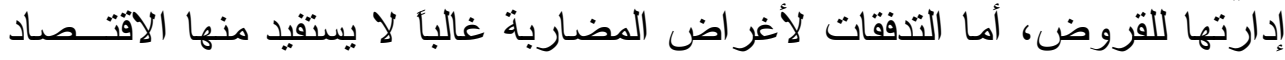

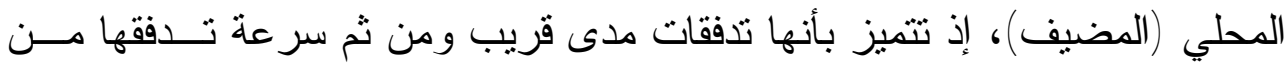

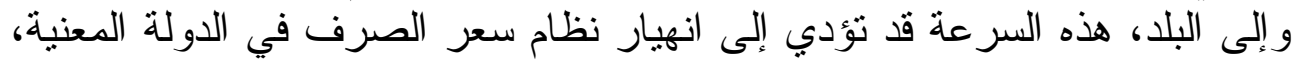

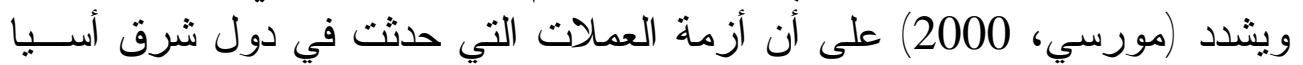

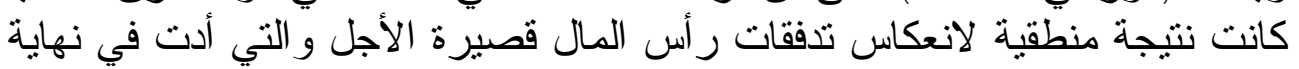

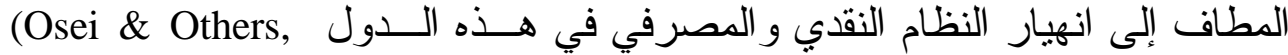
.2002, 1-4)

ثالثاً - نظرية تدفقات رأس المال الخاص (دوافع تدفق رأس المال)

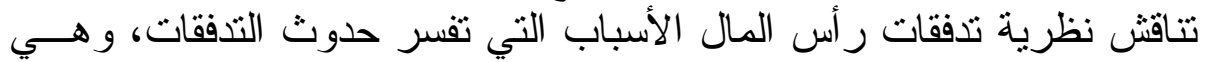

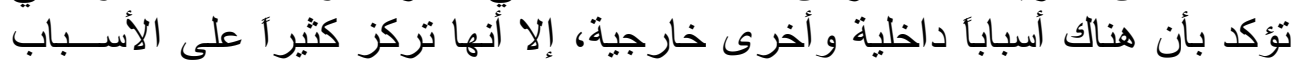

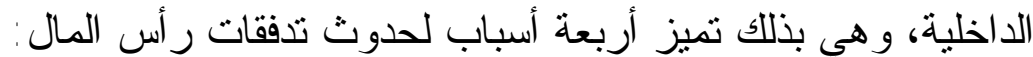

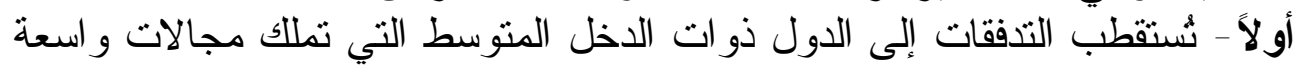

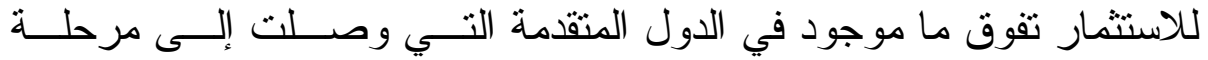

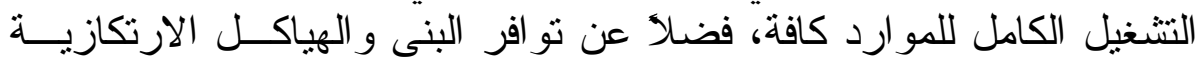
بخلاف الدول منخفضة الاخل التي تشكو من نقص كبير فيها.

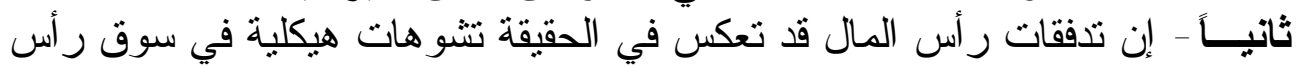

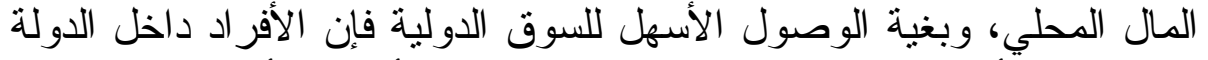

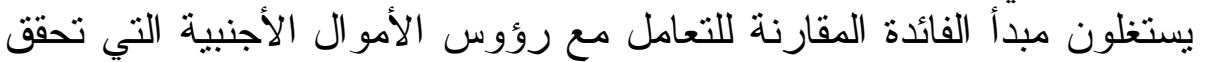

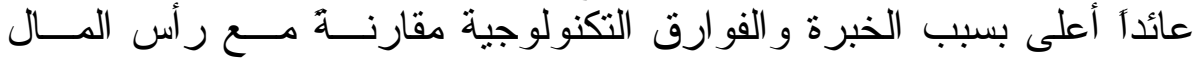
المحلي.

ثالثاً - قد لا تكفي مصادر التمويل المحلي لتغطية تكاليف التتمية الاقتصادية لــذلك فئل

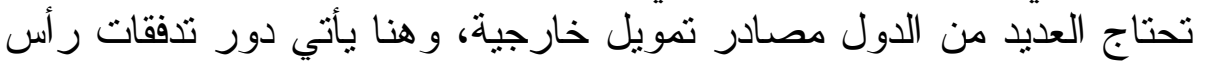

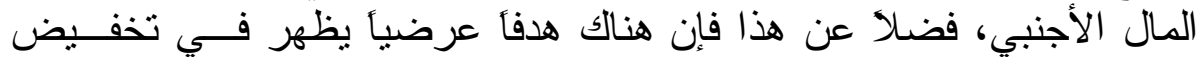

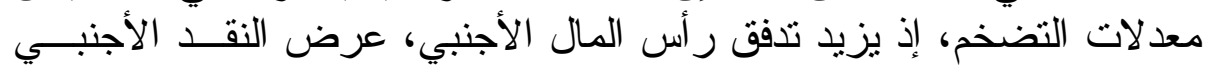
ومن ثم يزداد عرض النقد الحقيقي المحلي، وهذا يزيد من قيمة العملة العلة المحلية

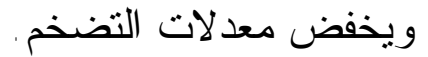

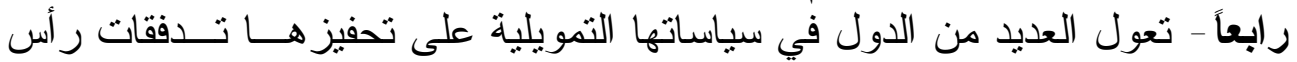

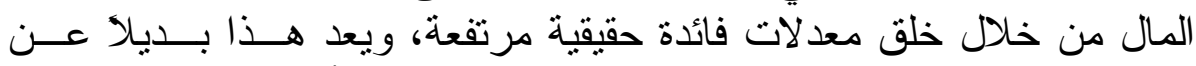

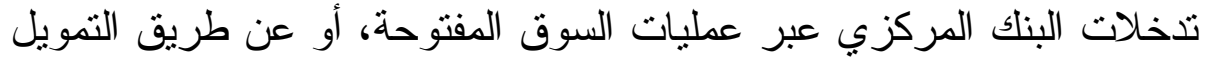

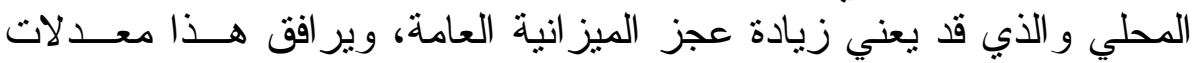




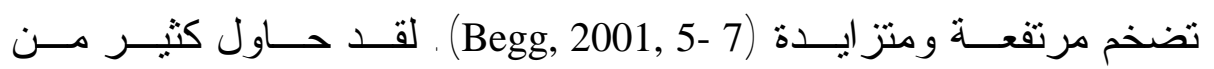

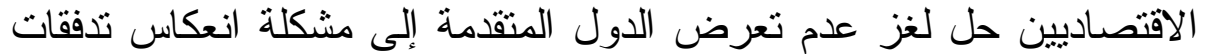

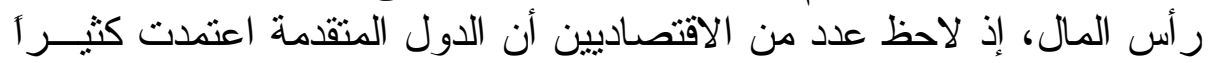

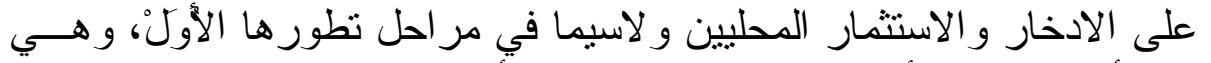

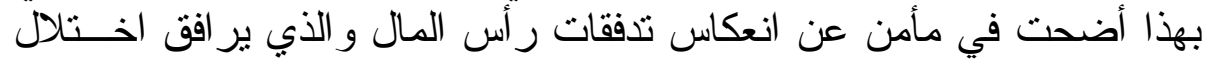

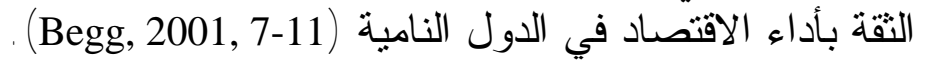

الاتجاهات التأثيرية للعو امل المحددة في تدفقات رأس المال الخاص التاص

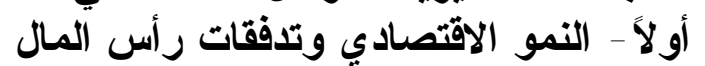

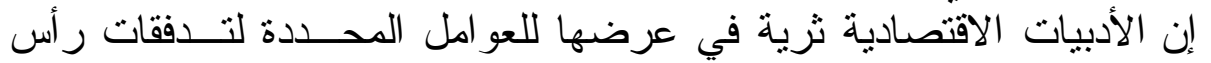

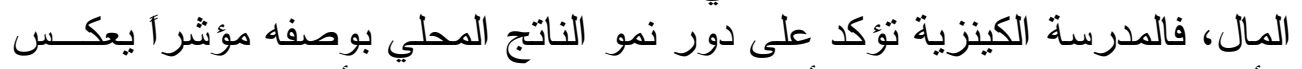

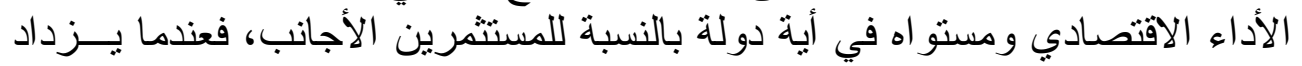

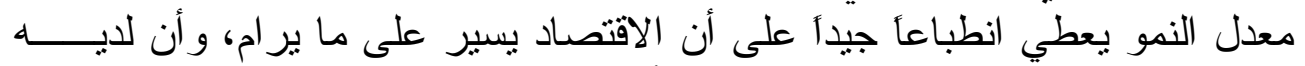

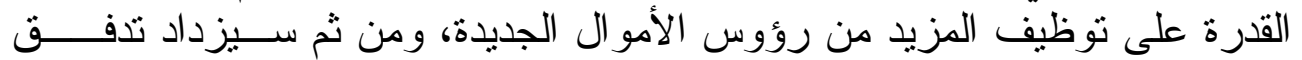

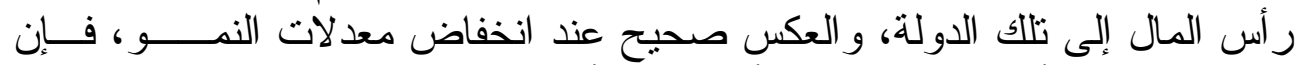

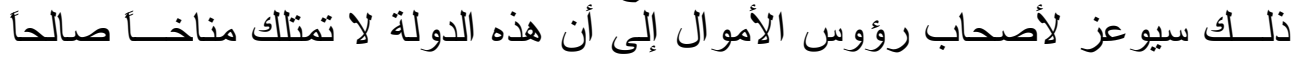

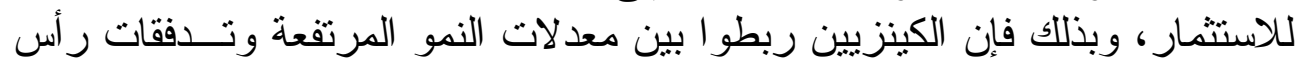

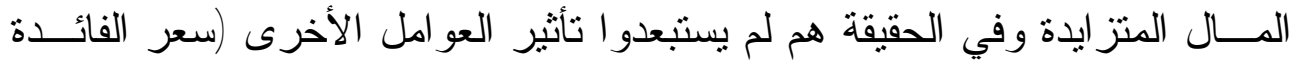

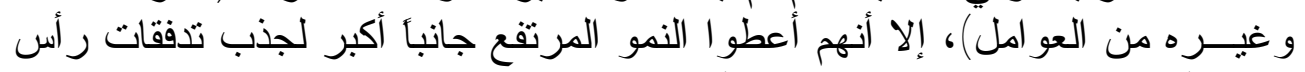

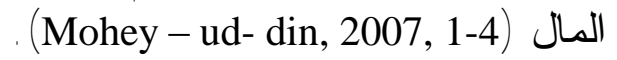

ثانياً - سعر الفائدة وتدفقات رأس المال الخاص

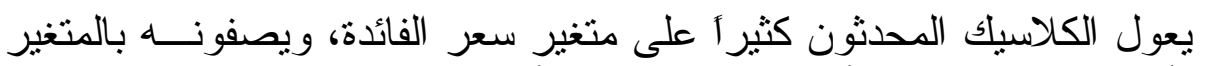

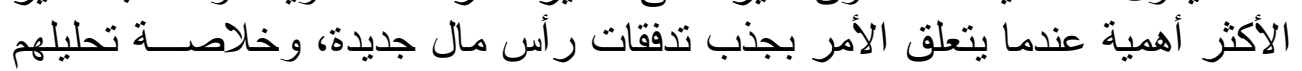

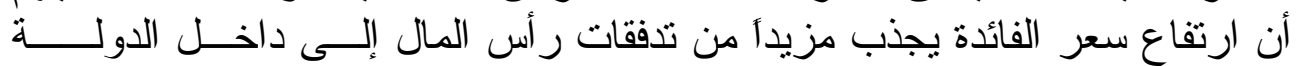

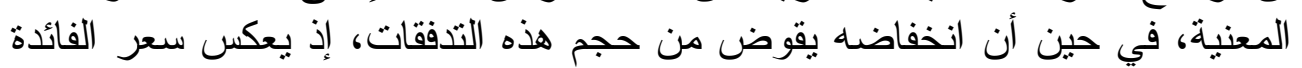

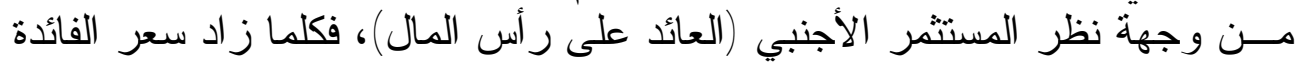

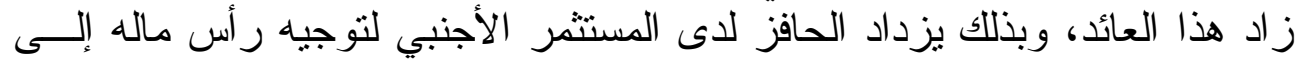
هذه الدولة (عبد العظيم، 2002، 7 -3 -3).

ثالثاً - تغيرات سعر الصرف وتدققات رأس المال

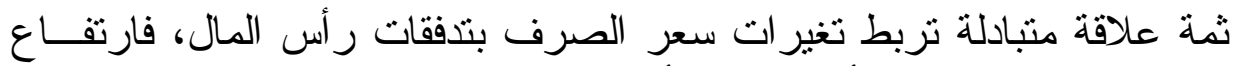

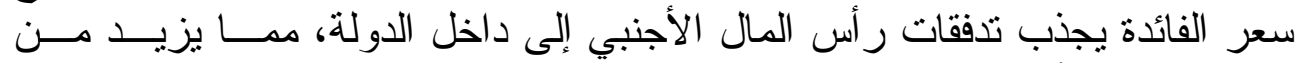

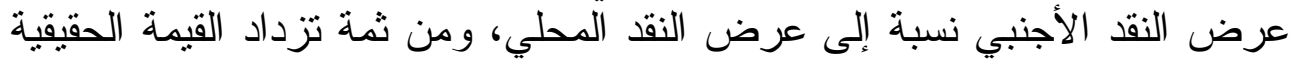

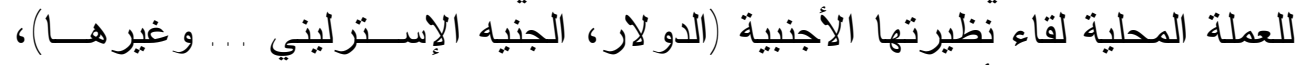

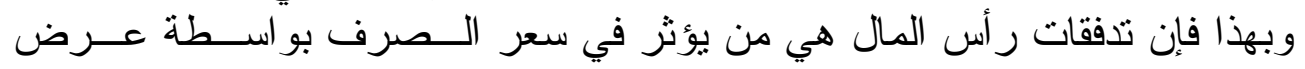




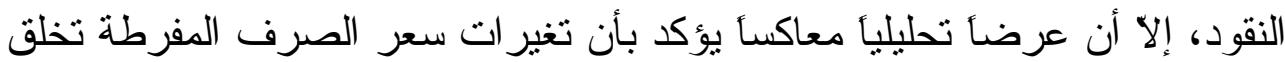

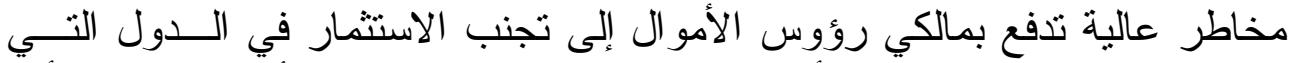

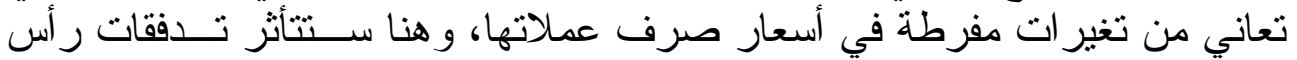

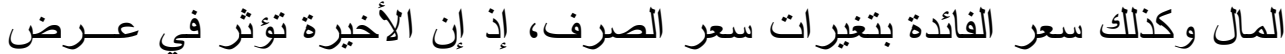

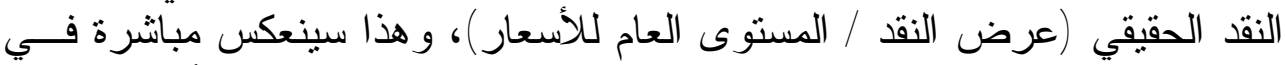

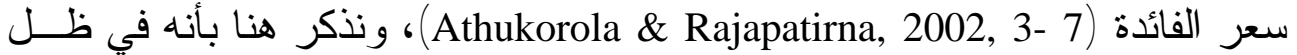

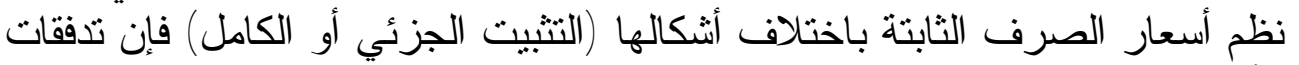

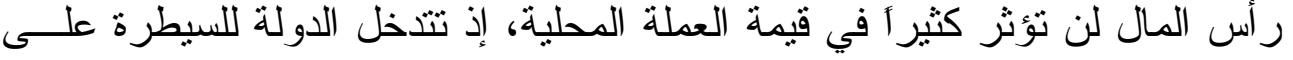

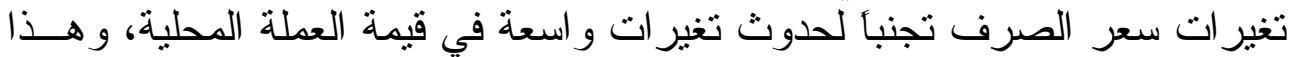

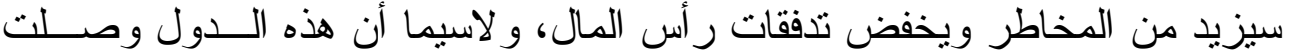

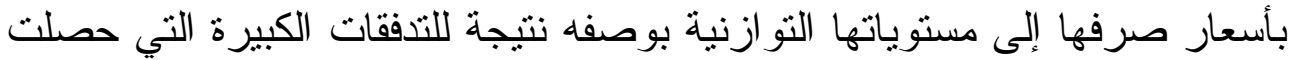
عليها في مر احل تطور ها الأول . لئل

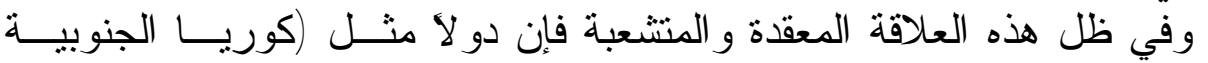

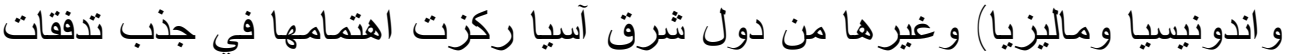

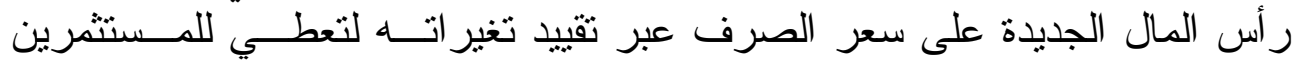

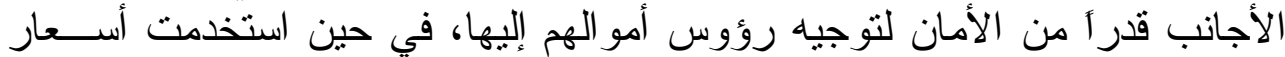

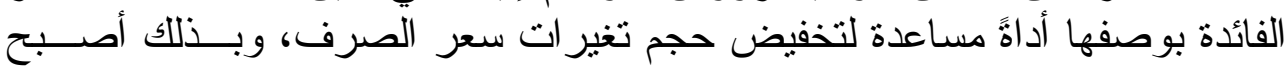

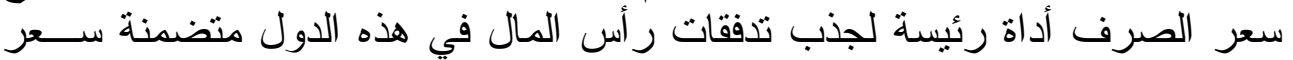

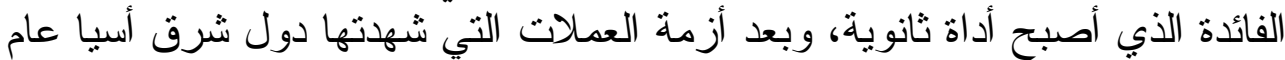

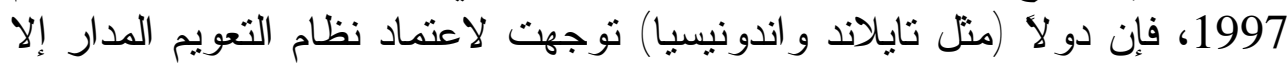

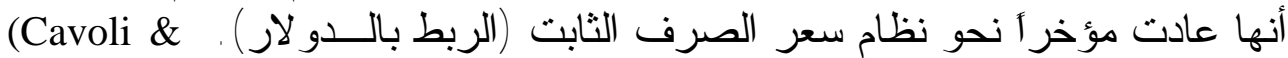

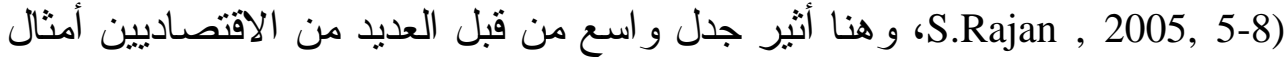

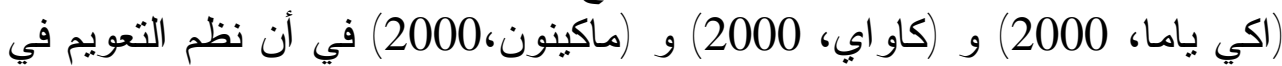

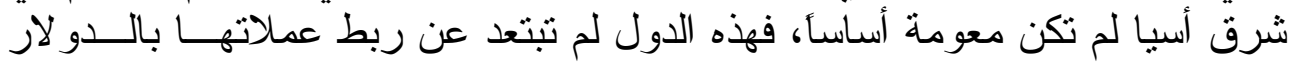
حتى بعد أزمة العملات عام (1997) (Fukuda, 2004, 71-75).

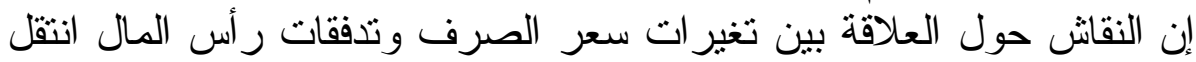

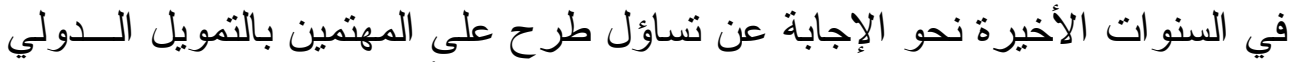

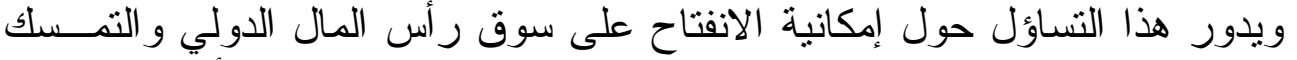

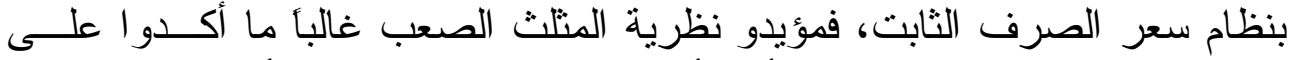

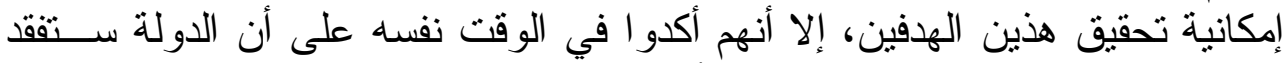

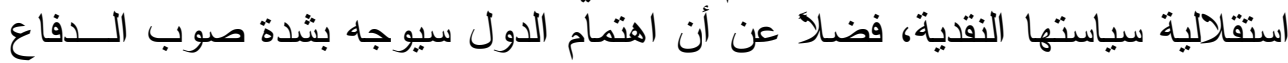
عن المثنتات (Joshi, 2003, 2-4)، إن أزمة العملات في شرق النيات أسيا كثفت استحالة

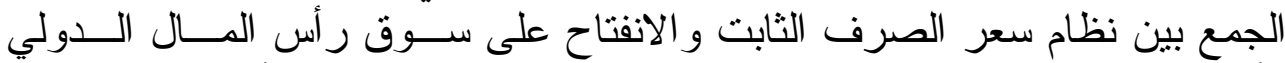

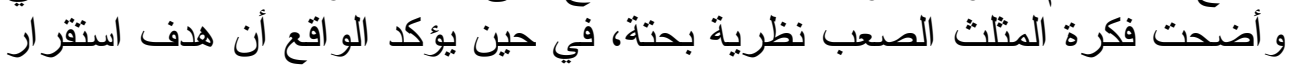

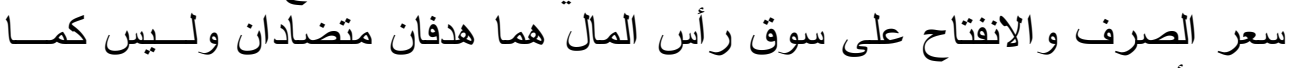
يدعي أنصار نظرية المتلث الصعب بإمكانية تحقيقهما معأ. 


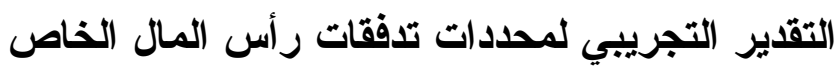

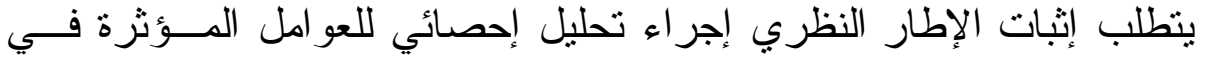
تدفقات ر أس المال، وقد وصف الأنموذج والجراء اختيرت متغير اته اعتماداً على النظرية

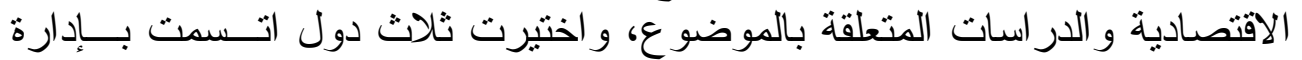

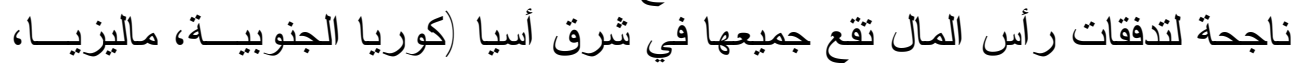

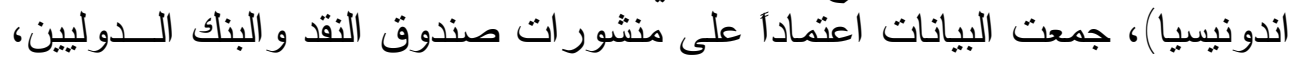
فضلا عن تقرير الاستثمار العالمي للعام 2006 الذي تصدرهات التهاد الاونكتاد .

أولاً - توصيف الأنموذج الإحصائي

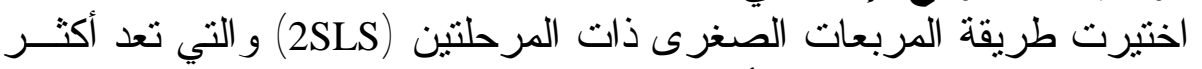
انسجاماً مع در استتا وقد وصف الأنموذج الإحصائي بالثكل الآتي: $\mathrm{EX}_{\mathrm{t}}=\mathrm{a}_{0}+\mathrm{b}_{1} \mathrm{G}+\mathrm{b}_{2} \mathrm{M}_{\mathrm{t}}+\mathrm{b}_{3} \mathrm{Cap}+\mathrm{e}_{\mathrm{i}}$

$\mathrm{Cap}=\mathrm{a}_{0}+\mathrm{b}_{1} \mathrm{gr}+\mathrm{b}_{2} \mathrm{r}+\mathrm{b}_{3} \mathrm{EX}_{\mathrm{t}}+\mathrm{e}_{\mathrm{i}}$

حيث ان:

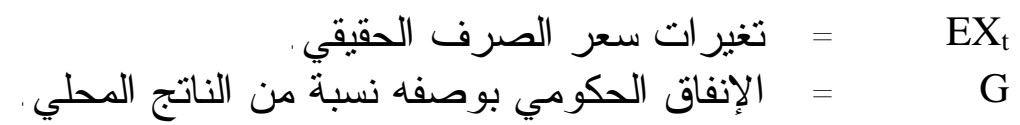

= عرض النقود بوصفه نسبة من الناتج المحلي.

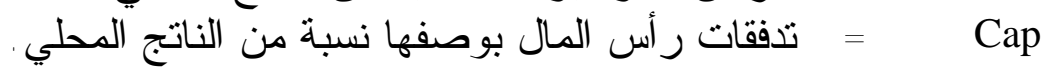

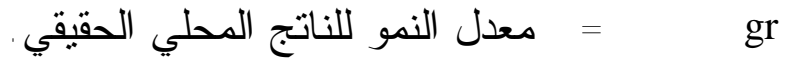
= r

= تغير ات سعر الصرف الحقيقي التي قدرت بالمرحلة 1 = EX = $=\left(b_{1}-b_{3}\right)$

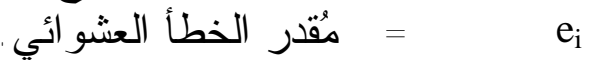
ثانياً - تفسير النتائج الخاصة بكورياً الجنوبية

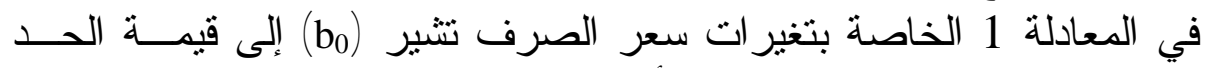

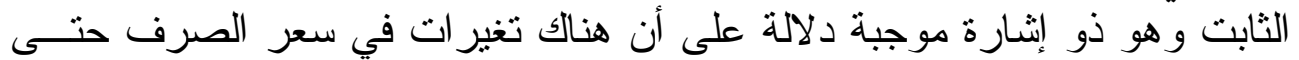

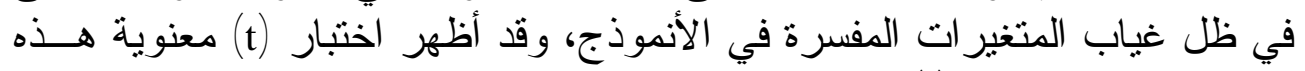

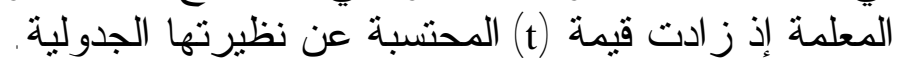

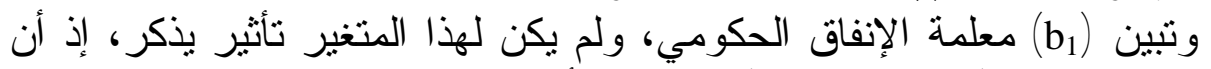

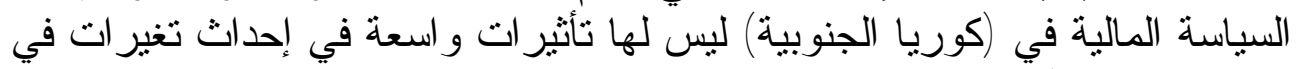

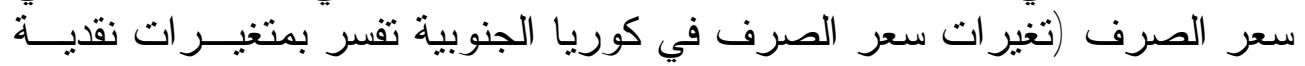

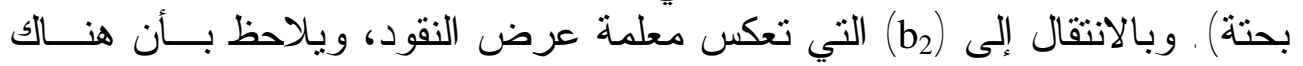
تأثير ات ايجابية ومعنوية لعرض النقان النقود في تغير ات سعر الصرف، وقد بلغنت قيمة 


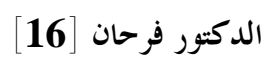

هذه المعلمة (0.77)، أي إن زيادة عرض النقود بنسبة (17\%) ثُحدِث تغيرات فـي

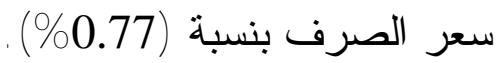
وتبين (b3) معلمة تدفقات رأس المال، ولم يكن لهذا المتغير أهمية تذكر، أي لهي

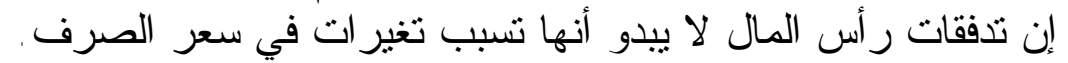

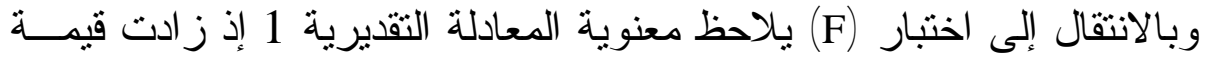

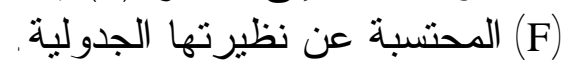

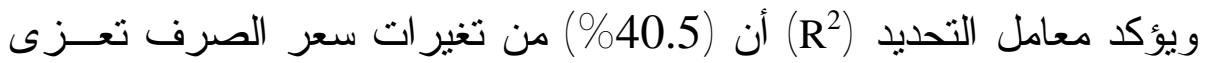

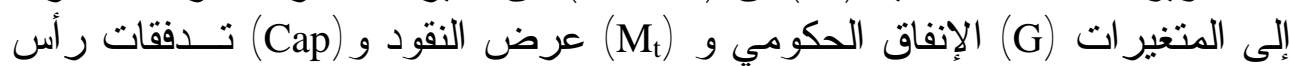

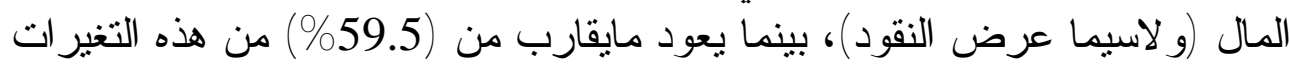

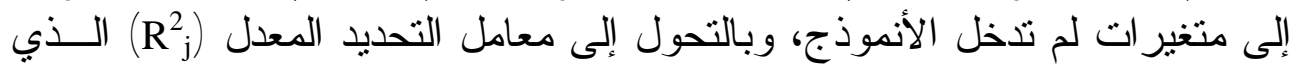

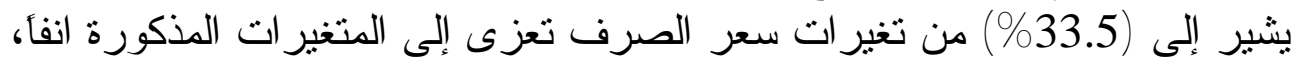
في حين تعزى (66.5\%) إلى متغير ات ات لم تدخل الأنموذج.

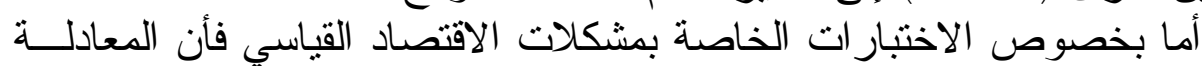

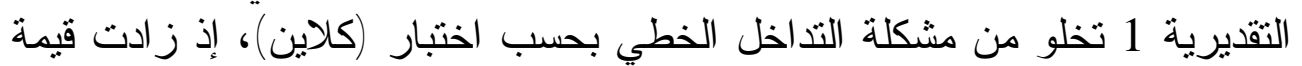
معامل الارتباط الكلي (R) عن معاملات الأرتباط الجزئي.

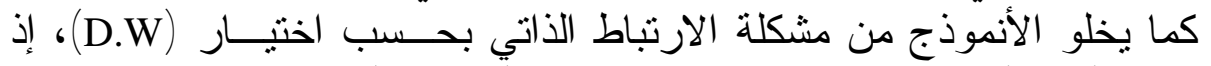
وقعت قيمة (D.W) في منطقة قبول فرضية العدم (H) وجود هذه المشكلة.

وبالانتقال إلى المعادلة التقديرية الثانية:

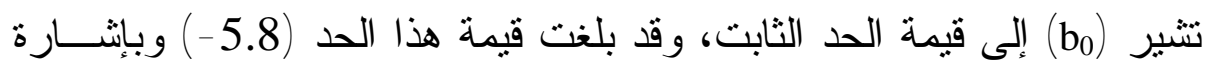

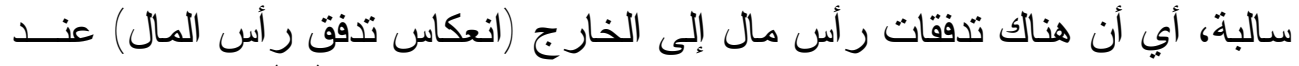

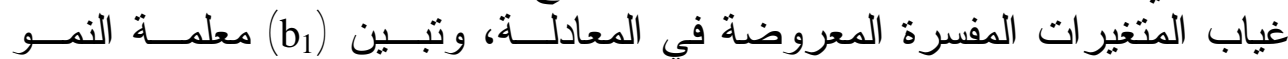

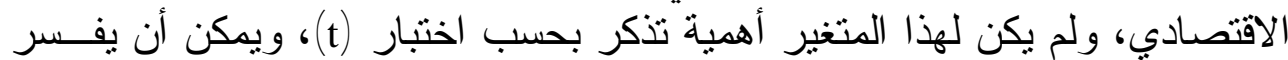

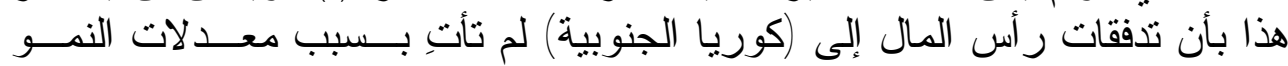

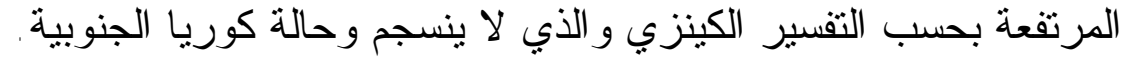

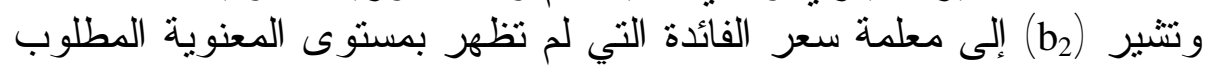

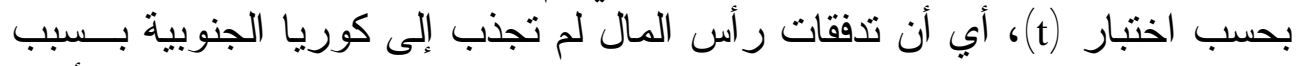

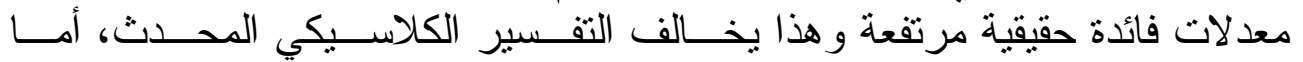

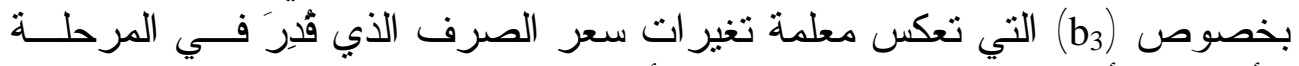

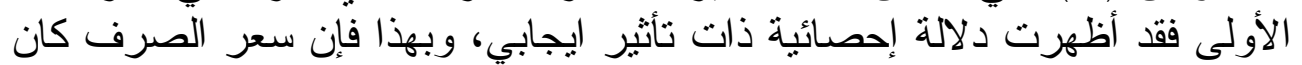

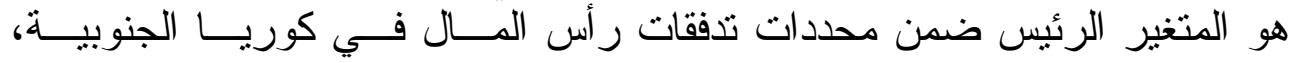

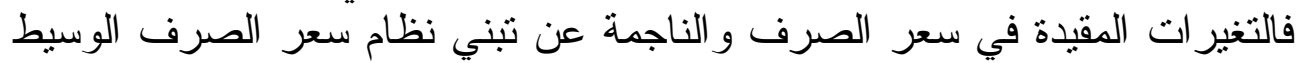

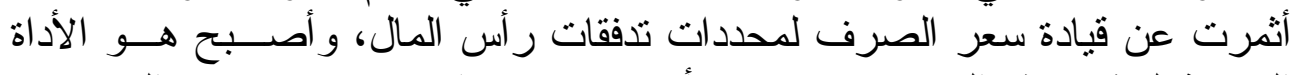

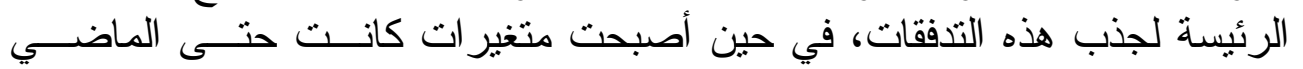


القريب تعد نواة هذه المحددات (سعر الفائدة) متغير ات مساعدة لسعر الصرف فـي

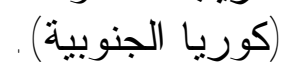

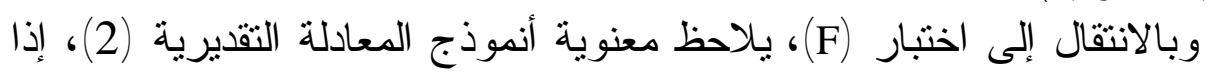

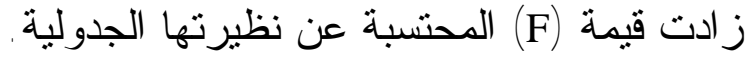

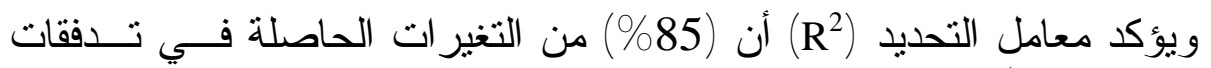

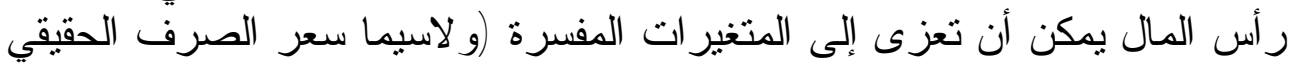

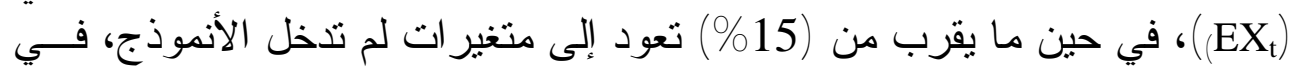

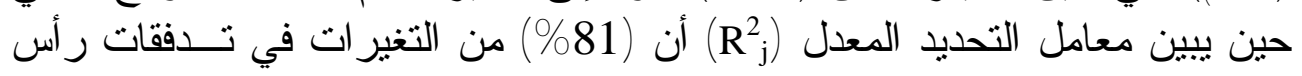

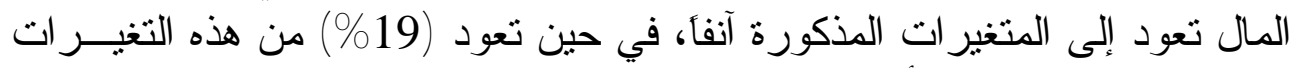
إلى متغير ات لم تدخل الأنموذج المبن.

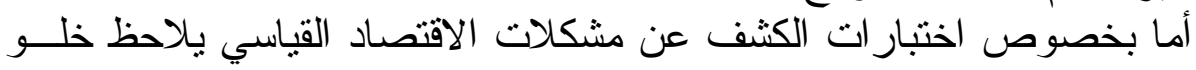

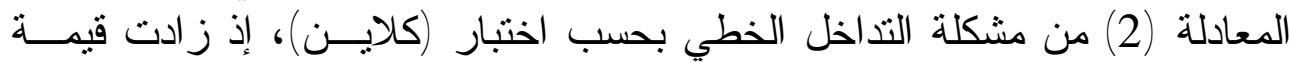

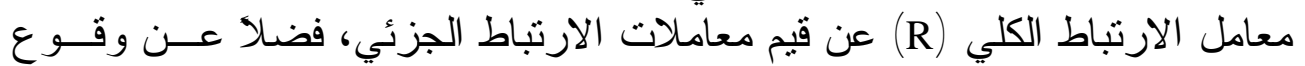

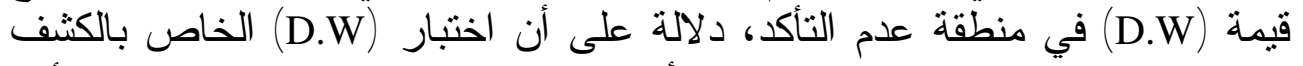

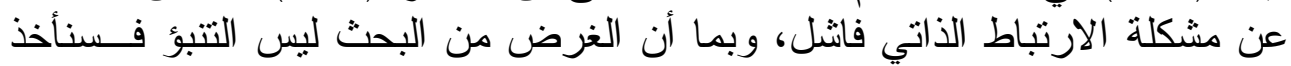
بمقدر ات هذه المعادلة.

ثالثاً - تفسير النتائج الخاصة بماليزيا

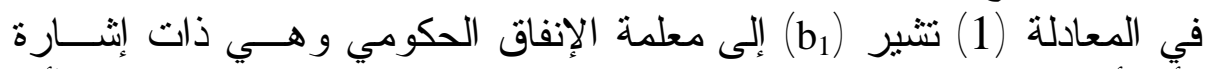

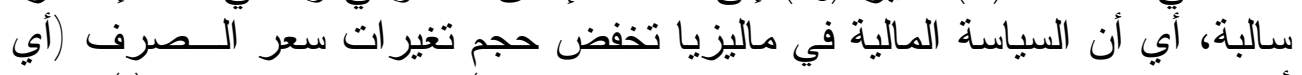

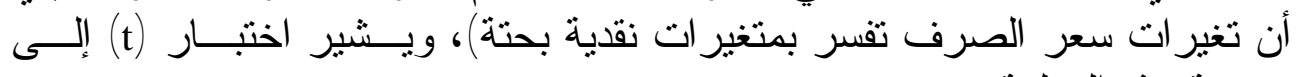
معنوية هذه المعلمة.

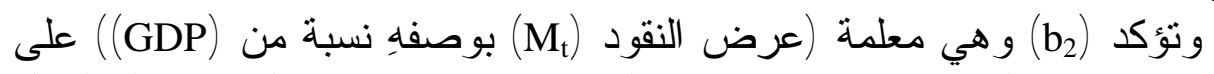

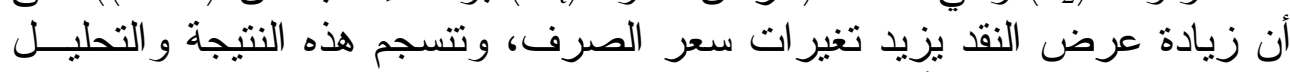

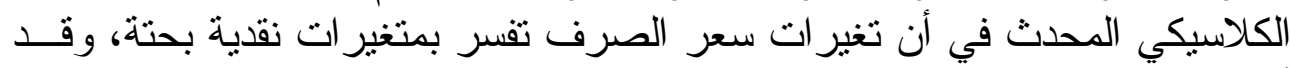

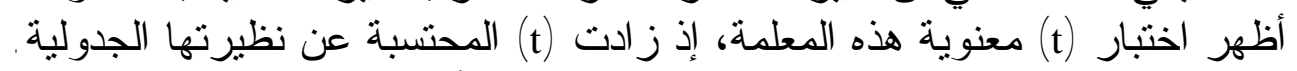

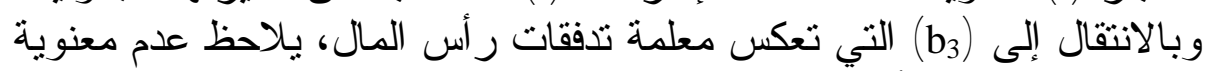

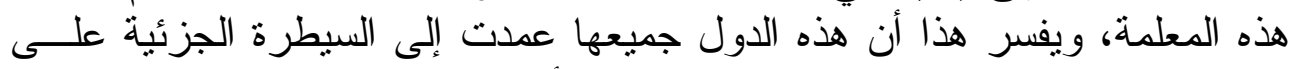

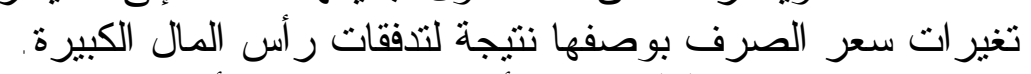

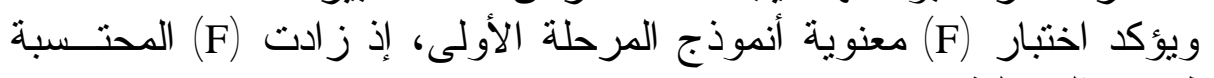

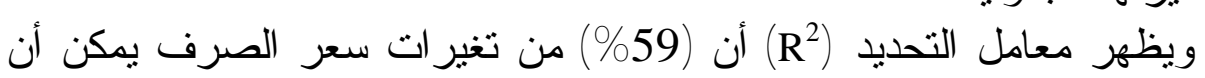

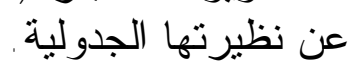

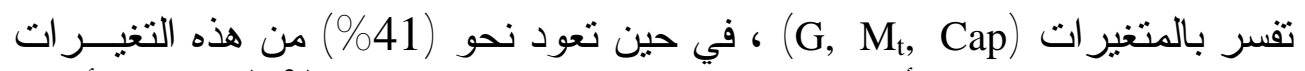

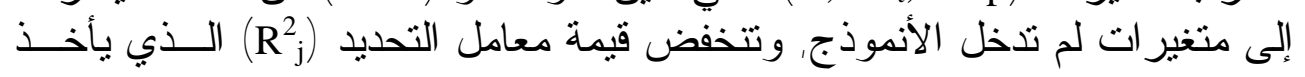

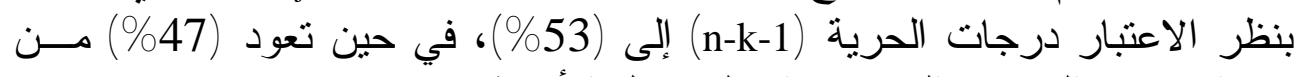
تغير ات سعر الصرف إلى متغير ات لم تدخل الأنموذج. 


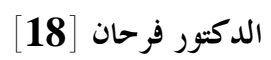

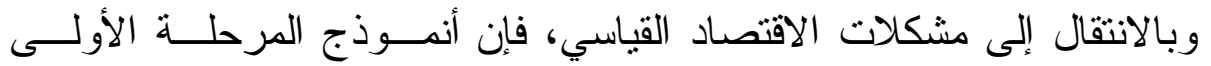

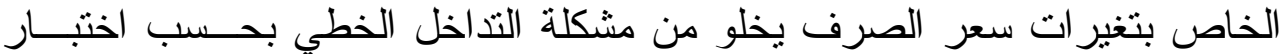

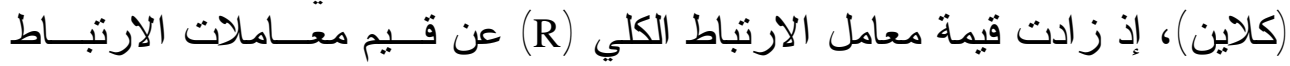
ويشير اختبار داربن وانسن (D.W) إلى أنه لا يمكن الجزم بوجود المشكلة

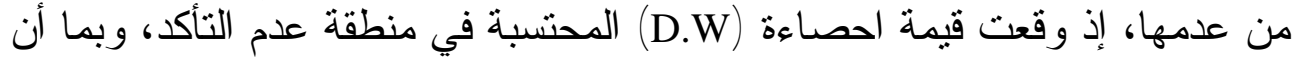

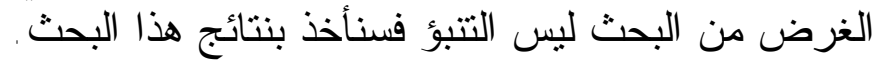

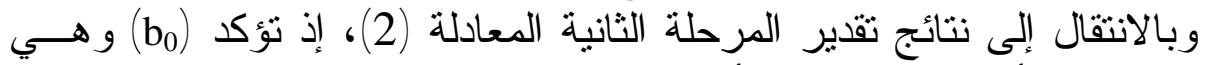

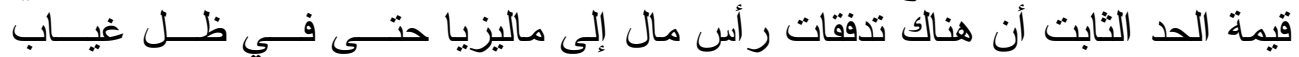

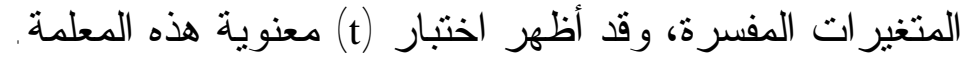

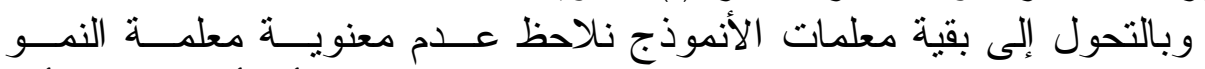

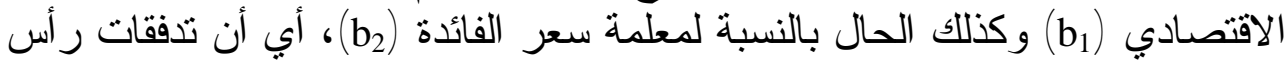

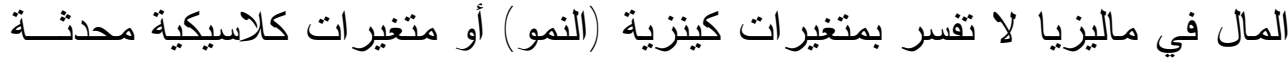

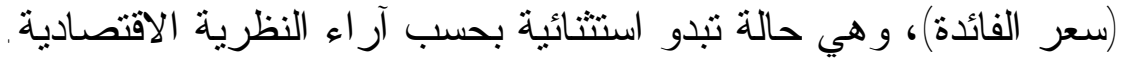

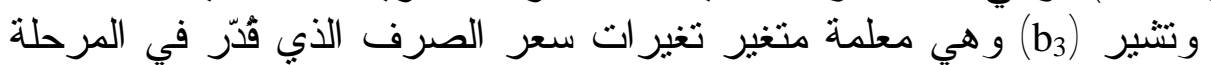

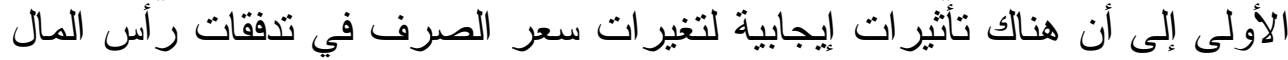

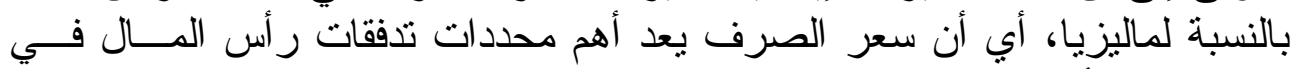

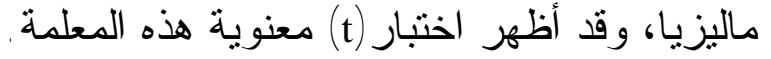

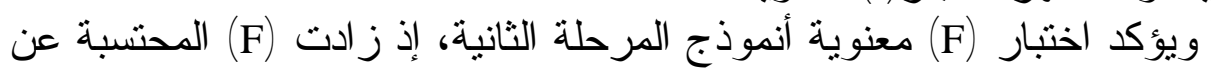

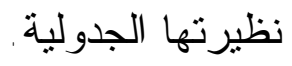

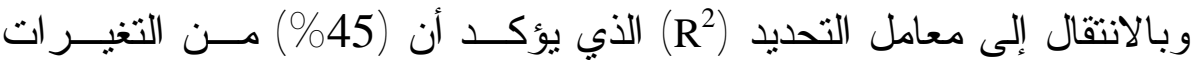

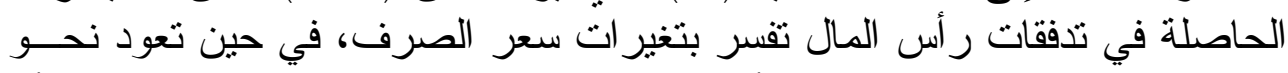

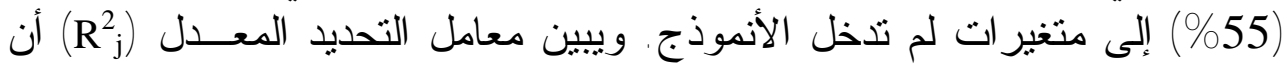

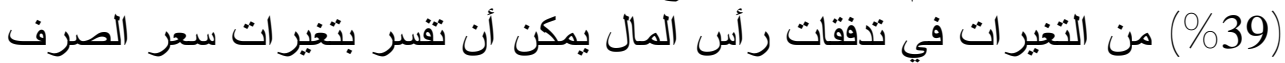

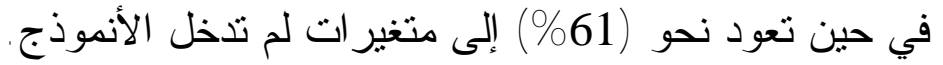

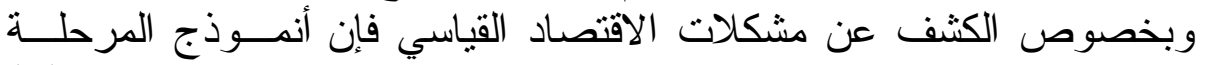

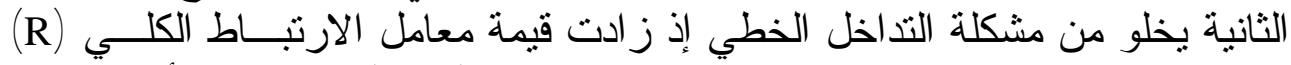

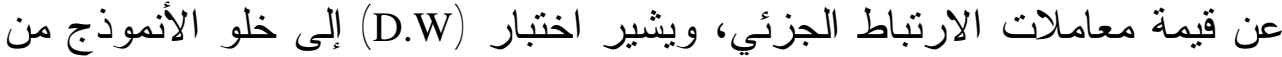

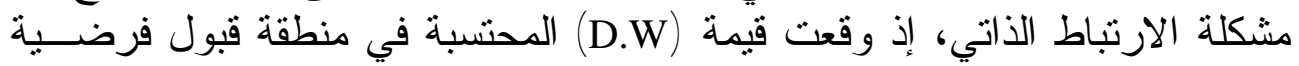

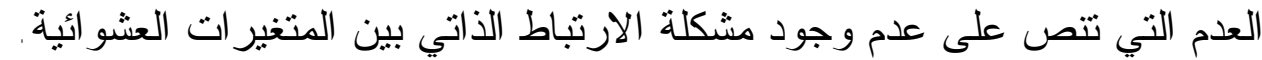

\section{رابعاً - تفسير النتائج الخاصة بأندونوسيا}

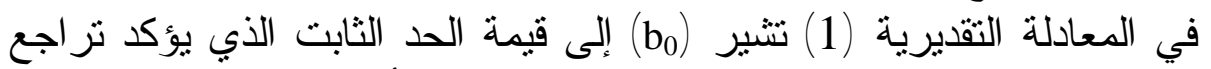

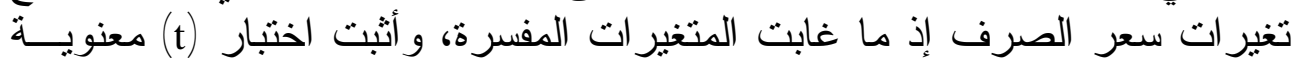




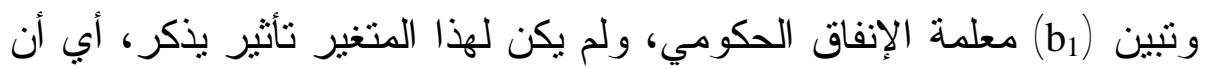

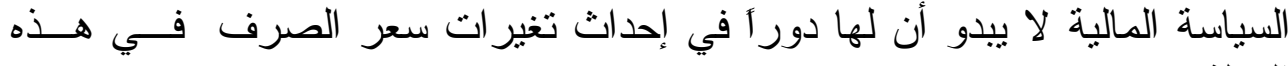

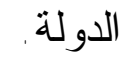

ونتير (b2) إلى معلمة عرض النقود (Mt) وقد كان تأثير هذا المتغير إيجابياً

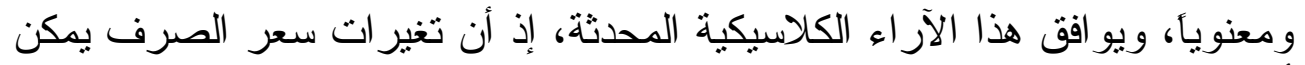

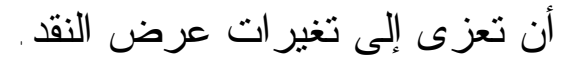

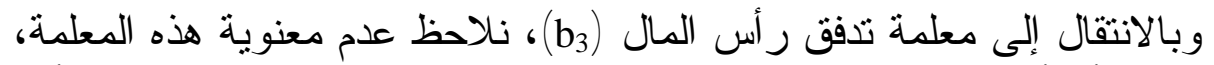

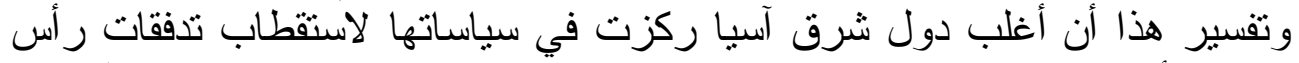

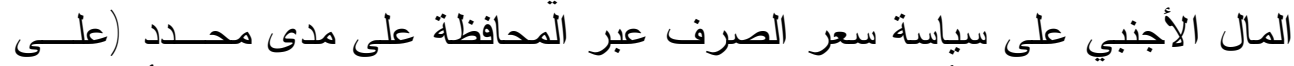

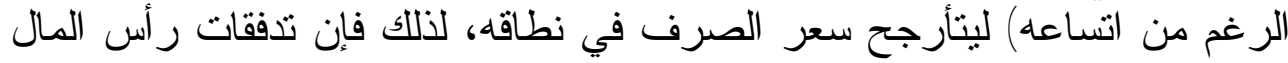

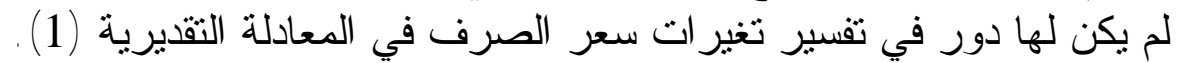

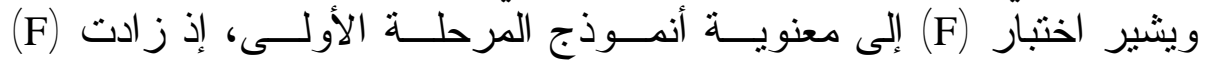

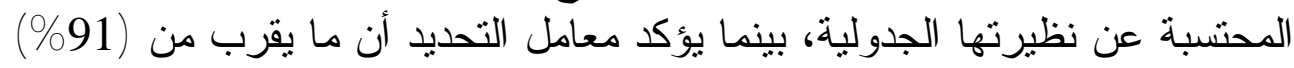

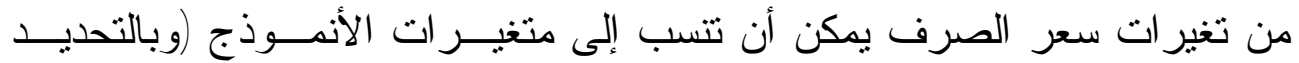

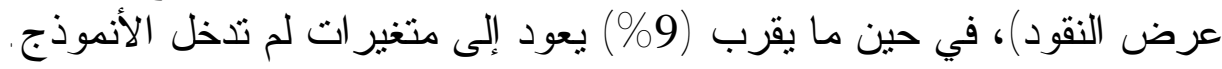

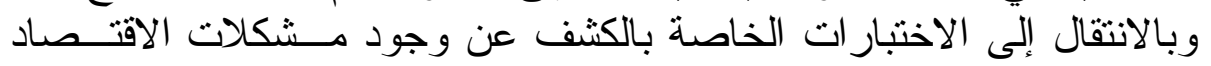

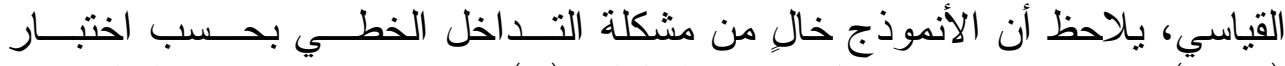

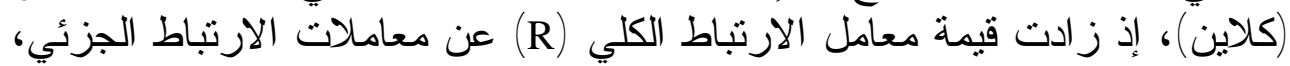

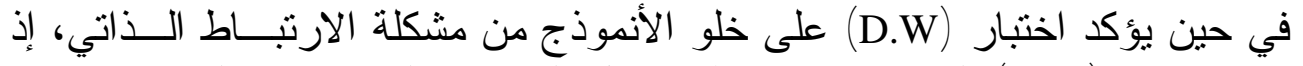

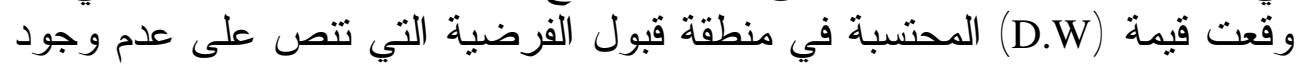
هذه المشكلة (بخيت وفتح الله ، 2002، 188 الهن -223).

\begin{tabular}{|c|c|c|c|c|c|c|c|c|}
\hline \multicolumn{9}{|c|}{ 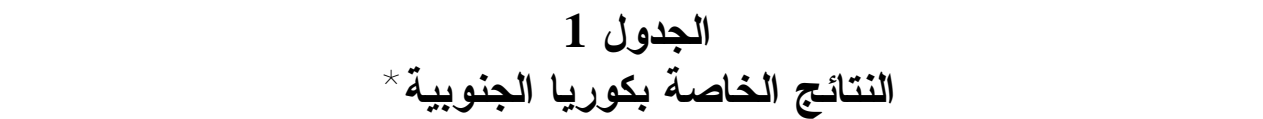 } \\
\hline المعادلة & $b_{0}$ & $b_{1}$ & $\mathbf{b}_{2}$ & $\mathbf{b}_{3}$ & $\mathbf{F}$ & $\mathbf{R}^{2}$ & $\mathbf{R}_{\mathbf{j}}$ & D.W \\
\hline $\begin{array}{c}1 \\
(\mathrm{t})\end{array}$ & $\begin{array}{l}3.75 \\
(2.4)\end{array}$ & $\begin{array}{r}-0.12 \\
(0.17)\end{array}$ & $\begin{array}{c}0.77 \\
(1.77)\end{array}$ & $\begin{array}{c}0.14 \\
(0.55)\end{array}$ & 6.4 & 43.5 & 35.5 & 1.99 \\
\hline $\begin{array}{l}2 \\
(\mathrm{t})\end{array}$ & $\begin{array}{c}-5.8 \\
(-5.4)\end{array}$ & $\begin{array}{c}(-0.4) \\
(-0.74)\end{array}$ & $\begin{array}{l}0.07 \\
0.85\end{array}$ & $\begin{array}{c}1.15 \\
(7.65)\end{array}$ & 24.5 & $\% 85$ & $\% 81.3$ & 1.57 \\
\hline
\end{tabular}

* استخدت الدالة الخطية الني أعطت أفضل توفيق لمعادلة الانحدار .

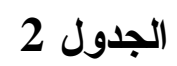

النتائج الخاصة بماليزيا

\begin{tabular}{|c|c|c|c|c|c|c|c|c|}
\hline المعادلة & $\mathbf{b}_{\mathbf{0}}$ & $\mathbf{b}_{\mathbf{1}}$ & $\mathbf{b}_{\mathbf{2}}$ & $\mathbf{b}_{\mathbf{3}}$ & $\mathbf{F}$ & $\mathbf{R}^{\mathbf{2}}$ & $\mathbf{R}_{\mathbf{j}}$ & D.W \\
\hline 1 & 1.54 & -0.61 & 0.3 & 0.06 & 9.63 & 59 & 53 & 1.54 \\
\hline
\end{tabular}




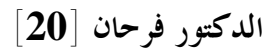

\begin{tabular}{|c|c|c|c|c|c|c|c|c|}
\hline$(\mathrm{t})$ & $(1.6)$ & $-(3.4)$ & $(2.64)$ & $(0.64)$ & & & & \\
\hline 2 & 1.12 & -0.05 & 0.04 & 0.11 & \multirow{2}{*}{12.5} & 45 & 3 & \multirow{2}{*}{1.87} \\
$(\mathrm{t})$ & 1.82 & -0.3 & 0.26 & 2.41 & & & \\
\hline
\end{tabular}

الجدول 3

النتائج الخاصة بأندونوسيا

\begin{tabular}{|c|c|c|c|c|c|c|c|c|}
\hline (المعادل| & $\mathbf{b}_{\mathbf{0}}$ & $\mathbf{b}_{\mathbf{1}}$ & $\mathbf{b}_{\mathbf{2}}$ & $\mathbf{b}_{\mathbf{3}}$ & $\mathbf{F}$ & $\mathbf{R}^{\mathbf{2}}$ & $\mathbf{R}_{\mathbf{j}}$ & $\mathbf{D . W}$ \\
\hline $\begin{array}{c}1 \\
(\mathrm{t})\end{array}$ & $\begin{array}{c}-5.5 \\
(-2.55)\end{array}$ & $\begin{array}{c}1.97 \\
1.6\end{array}$ & $\begin{array}{c}1.9 \\
(6.8)\end{array}$ & $\begin{array}{c}0.1 \\
0.76\end{array}$ & 67.8 & 91.1 & 89.5 & 1.41 \\
\hline $\begin{array}{c}2 \\
(\mathrm{t})\end{array}$ & $\begin{array}{c}-5.73 \\
(-6.27)\end{array}$ & $\begin{array}{c}0.22 \\
(-1)\end{array}$ & $\begin{array}{c}-0.35 \\
-1.66\end{array}$ & $\begin{array}{c}1.05 \\
(7.7)\end{array}$ & 23 & 79.3 & 76 & 1.85 \\
\hline
\end{tabular}

النتائج و والمقترحات

أولاًا - النتائج

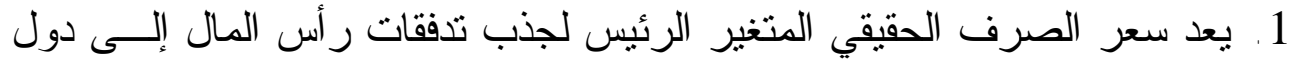

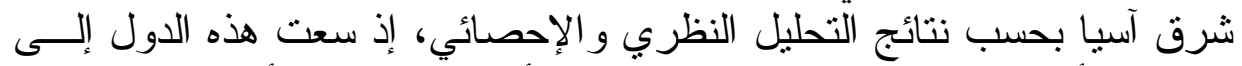

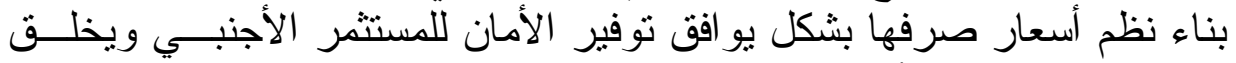

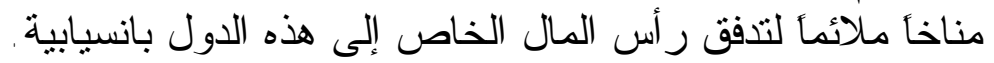

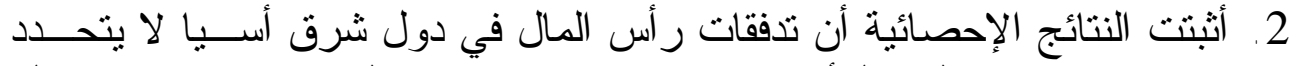

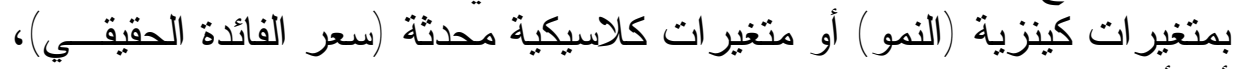

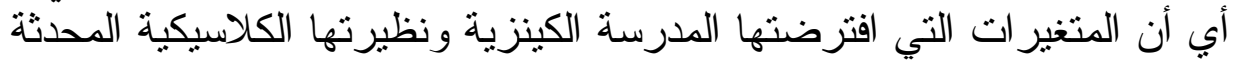

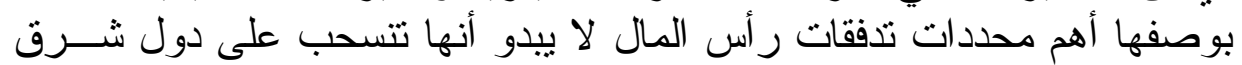
3. تفسر تغير ات أسعار صرف بمتغير ات السياسة النقدية (عرض النقود)، في حين

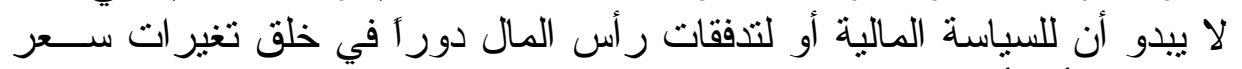

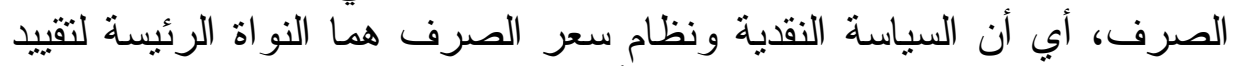
تغير ات سعر الصرف وجذب الدفيات النفات رأسمالية جديدة.

\section{ثانياً - المقترحات}

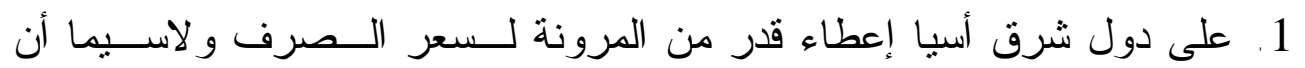

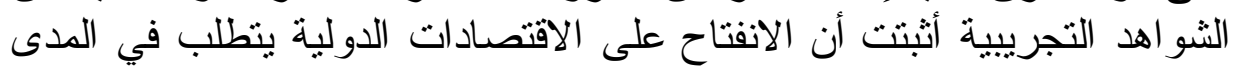

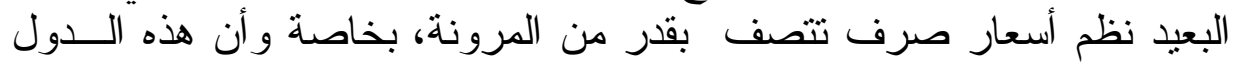

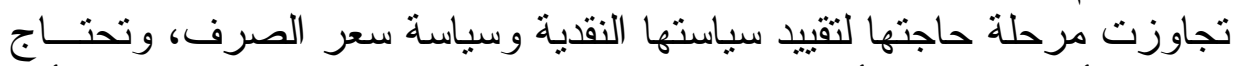
إلى نظم أسعار صرف أكبر مرونة إذا ما فكرت بجدية الأندماج في سوق رأس ونس

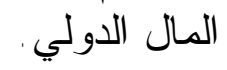



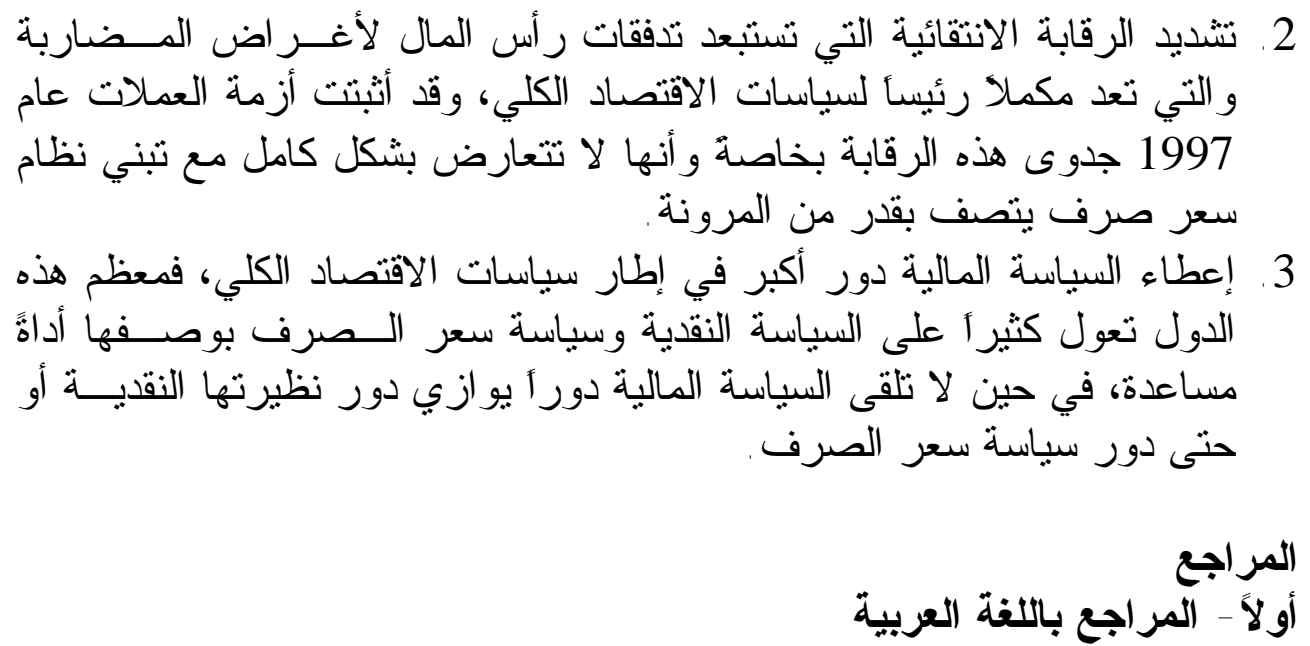

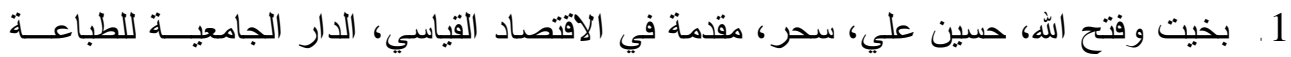

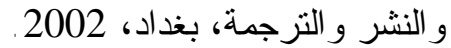

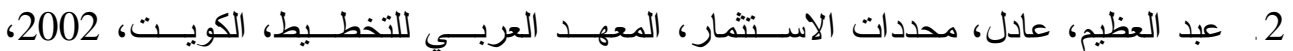
.www.arab-api.org

3. هاجن، أفيرت، اقتصاديات التتمية، ترجمة: جورج خوري، مركز الكتب الأردني، عهــان،

\section{ثانياً - المراجع باللغة الاجنبية}

1. Athukorala \& Rajapatirana, Prema- Chandra \& Sarath, Capital inflows \& the real exchange rate: A comparative Study of Asia \& Latin America,

Email: prema- Chandra. athukorala @ anu.edu

2. Begg, David, Capital Inflows, Monetary policy \& Exchange Regime, Working papers, No: 1, Macroeconomic Studies, International Center for Economic Growth, 2001

Email: dbegg@econ.bbk.ac.uk.

3. Cavoli \& S.Rajan Tony \& Ramkishe, The Capital in Flows problem in selected Asian economics in the $1990_{\mathrm{s}}$ Revisited, 2005,

Email:tony.cavoli@udelaide-edu.au, \& $\underline{\text { rrajan@ @nus.edu. Sg }}$

4. Fukuda, Shin - ichi, Post - Crisis Exchange Rate Regime in East Asia, 2004.

Email: sfukud@e.putoky. ac.jp.

5. IMF, International Financial Statistics, Washington, 2003, CD-Rom.

6. IMF, International Financial Statistics, Washington, 2006. www.IMF .org.

7. Joshi, Vijan, Financial Globali- sation, Exchange Rates \& Capital controls in Developing countries, 2003.

Email: vijay.joshi@merton.ox.ac.uk.

8. Mohey-ud-din, Ghulam, Impact of Foreign Capital Inflows on Economic Growth In Pakistan (1975-2004), Munich personal RepEc Archive, MPRA paper No.1233, 2007. http: //Mpra.ub.uni-Muenchen.de /1233/.

9. Osei, Morrissey \& Lensink, Robert, Oliver \& Robert,The volatility of Capital Flows: Measures \& Trends For Developing Countries, Centre of Research in Economic Development \& International Trade, University Nottingham, No: 2/20,2003.

www.nottingham.ac.uk / economics / research / credit . 
الدكتور فرحان [22]

10. Unctad, World Investment Report: FDI From Developing \& Transition. Economics: Implications For Development, Annexes A \& B Definitions \& Sources unctad, New York \& Geneva, 2006.

www.unctad.org.

11. World bank, World Development Indicators, Washington, 2006.

www.worldbank.org.

12. World bank, World Development Indicators, Washington, CD-Rom, 2006. 